\title{
Microstructure and mechanical behaviour of additive manufactured Ti-6Al-4V parts under tension
}

\author{
Alexey Panin ${ }^{1, *}$, Marina Kazachenok ${ }^{1}$, Alexey Kolmakov $^{2}$, Sergey Chizhik $^{3}$, Mikhail \\ Heifetz, ${ }^{4}$ and Yuri Chugui ${ }^{5}$ \\ ${ }^{1}$ Institute of Strength Physics and Materials Science of the SB RAS, 634055 Tomsk, Russia \\ ${ }^{2}$ Baikov Institute of Metallurgy and Materials Science of RAS, 19334 Moscow, Russia \\ ${ }^{3}$ A.V. Luikov Heat and Mass Transfer Institute of NAS of Belarus, 220072 Minsk, Belarus \\ ${ }^{4}$ SSPA "Center" NAS of Belarus, 220072 Minsk, Belarus \\ ${ }^{5}$ Tecnological Design Institute of Scientific Instrument Engineering, 630058 Novosibirsk, Russia
}

\begin{abstract}
Metal-based additive manufacturing technologies using electron or laser beams as a heat source for melting a metal powder or wire have been the subject of keen interest in recent years. At present paper a comparative analysis of the microstructure, strain response during tensile test and mechanical properties of $\mathrm{Ti}-6 \mathrm{Al}-4 \mathrm{~V}$ samples produced by selective laser melting, electron beam melting or electron beam free-form fabrication were performed. A microstructural study using transmission electron microscopy revealed columnar prior $\beta$ grains transformed into a lamellar $\alpha$-morphology in the samples. According to X-ray diffraction study, the volume fractions of the $\beta$-Ti phase in the samples were equal to 2,4 and $6 \%$ respectively. It has been shown that the Vickers microhardness of SLM and EBM Ti-6Al-4V samples was similar $(\sim 5.4 \mathrm{GPa})$ while the hardness of $\mathrm{EBF}^{3}$ parts was significantly lower $(4.5 \mathrm{GPa})$. The uniaxial stress-strain response of the Ti-6Al-4V samples fabricated by different additive manufacturing technologies were compared. Crystallographic (dislocation motion) and non-crystallographic (shear banding) deformation mechanisms of the loaded samples were studied by scanning electron microscopy and optical profilometry.
\end{abstract}

\section{Introduction}

Metal-based additive manufacturing process is a novel and promising technique in which objects are formed by the electron beam or laser melting of metal powder or wire from 3D model data [1-3]. Each new layer is formed during 3D printing by the spreading of thin layer of powder feedstock on the baseplate followed by their selective melting or by continuous feeding of wire or powder feedstock into the molten pool. The benefits of electron-beam melting (EBM) include the ability to build titanium parts since the process realizes within vacuum environment. The latter is due to the high reactivity of titanium at

*Corresponding author: pav@ispms.ru 
elevated temperatures that may leads to a negative chemical interaction of titanium with oxygen, nitrogen and other gases on the environment. Besides, the microstructure of the parts produced by electron beam melting of powder feedstock from different materials often is better than that of the part produced by selective laser melting (SLM). However, as the electron beam spot diameter $(0.2-1.0 \mathrm{~mm})$ is bigger by one order of magnitude than the spot diameter of laser beam, surface finish and shape precision of EBM metal parts is often lower than that of SLM parts of the same material. Finally, nearly $100 \%$ efficient in feedstock consumption and extremely high build rate (up to $2500 \mathrm{~cm}^{3} / \mathrm{h}$ ) are the major advantages of electron beam free-form fabrication $\left(\mathrm{EBF}^{3}\right)$ process [4]. In this paper, we analyzed comparatively the microstructure, strain response during tensile test and mechanical properties of SLM-, EBM- and $\mathrm{EBF}^{3}$-produced Ti-6Al-4V samples.

\section{Experimental details}

SLM-samples were produced on the EOSINT M280 machine (EOS Electro Optical Systems, Munich, Germany), equipped with a CO laser. The powder of Ti6-Al-4V alloy of the Canadian company AP \& C was used and has an average particle size distribution of $50 \mu \mathrm{m}$. The experiments were performed in a chamber using argon gas as the shielding gas to prevent the melt pool from oxidation. Cuboid blanks with the dimensions of $10 \mathrm{~mm} \times 10 \mathrm{~mm}$ and height of $70 \mathrm{~mm}$ were vertically fabricated in an argon atmosphere on a 10 -mm thick titanium plate.

The EBM samples were produced from powder of titanium Ti-6Al-4V alloy (Ti6Al4V ELI) using ARCAM A2 EBM (Arcam AB, Mölndal, Sweden) machine. The powder was purchased from ARCAM AB. The powder particle size was varied from 50 to $150 \mu \mathrm{m}$. The detail of the process is described elsewhere [5].

$\mathrm{EBF}^{3}$ was performed using an electron beam welding machine, 6E400 (Teta, Tomsk). During the layer-additive process, a commercially available Titanium Grade 5 (Ti-6Al-4V) wire $1.6 \mathrm{~mm}$ in diameter was melted with a plasma power source onto the surface of a water-cooled titanium baseplate to build up a part. A detailed description of process parameters can be found elsewhere [6].

A JEM-2100 transmission electron microscope (TEM) was used for microstructural characterization of the samples. TEM samples were prepared by ion milling using Ion Slicer EM-09100IS. During preparation, argon was used as a working gas, the accelerating voltage was $8 \mathrm{kV}$, and the etching angle was $1.5^{\circ}$ to $4^{\circ}$.

The phase composition of the samples was determined using a Shimadzu XRD-7000 Xray diffractometer (XRD). XRD studies were performed with $\mathrm{CuK}_{\alpha}$ radiation $(1.5410 \AA$ wavelength) in conventional symmetric Bragg-Brentano geometry.

The Vickers microhardness was measured at the lateral surface of $\mathrm{Ti}-6 \mathrm{Al}-4 \mathrm{~V}$ alloy samples using the $50 \mathrm{~g}$ load for $10 \mathrm{~s}$.

Uniaxial quasi-static tension tests were conducted in air at room temperature using an INSTRON 5582 testing machine operated at a loading rate of $0.3 \mathrm{~mm} / \mathrm{min}$. Mechanical tests were performed with dumb-bell samples cut out of the XY plane (perpendicular to the build direction) by the electrical discharge machining. The gage section of the samples was $1 \mathrm{~mm}$ high, $5 \mathrm{~mm}$ wide, and $40 \mathrm{~mm}$ long. A LEO EVO 50 scanning electron microscope (SEM) and a New View 6200 optical profilometer were employed to investigate the surface roughening pattern of the loaded samples. Before loading, the samples were mechanical grinding using different grades of SiC emery papers ranging from 600 to 2000 grit, and then polished with the diamond past to nice shinny finish. 


\section{Results and Discussion}

\subsection{Microstructure}

Transmission electron microscopy studies of the SLM-fabricated Ti-6Al-4V parts reveal $\alpha^{\prime}$ phase martensitic plates inside columnar primary $\beta$-grains (Fig. 1,a). The average lateral size of the grains is equal to $200 \mu \mathrm{m}$ while their length reaches $600 \mu \mathrm{m}$. The dimensions of the martensitic $\alpha^{\prime}$ phase vary widely from 200 to $500 \mathrm{~nm}$. The defective substructure of martensitic lamellae is formed by a mesh dislocation structure, or by randomly located dislocations.
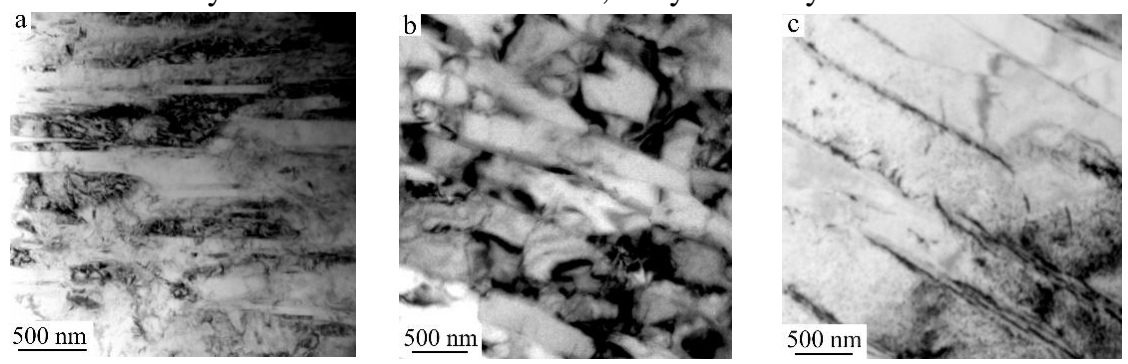

Fig. 1. TEM bright-field images of the microstructures of the SLM-(a), EBM-(b) and $\mathrm{EBF}^{3}$-produced Ti-6Al-4V sample.

The microstructure of the EBM- and $\mathrm{EBF}^{3}$-fabricated Ti- $6 \mathrm{Al}-4 \mathrm{~V}$ parts is quite similar. However the lateral size of the prior $\beta$ grains in the columnar structure of the EBMfabricated Ti-6Al-4V parts is less than $20 \mu \mathrm{m}$ while their average length does not exceed $200 \mu \mathrm{m}$. The lamellar $\alpha$-phase with the transverse plate size of $0.2-0.6 \mu \mathrm{m}$ and $\beta$ phase both in the form of plates and globular grains of $0.15-0.2 \mu \mathrm{m}$ size embedded in the grain boundaries of $\alpha$-phase are observed in the prior $\beta$ grains (Fig. 1,b). It is worth noting that the large number of extinction contours is presented in the TEM image showing high residual strain within the sample [3].

The columnar prior $\beta$ grains in the $\mathrm{EBF}^{3}$-produced $\mathrm{Ti}-6 \mathrm{Al}-4 \mathrm{~V}$ sample reach several millimetres in length while their lateral size varies between $500 \mu \mathrm{m}$ and $1 \mathrm{~mm}$. The massive martensite structure of $\mathrm{EBF}^{3}$-fabricated Ti-6Al-4V parts are shown in Figure 1,c. Massive martensite consisting of large irregular zones $(5-10 \mu \mathrm{m}$ in size) divided across into approximately $2 \mu \mathrm{m}$ thick $\alpha$-lathes. The $\alpha$-lathes consist of the 200 to $300 \mathrm{~nm}$ thick $\alpha$-lathes separated by the retained $\beta$ phase [4].

$\mathrm{X}$-ray diffraction in the Bragg-Brentano focusing geometry affords us the opportunity to reveal differences in the microstructure and phase composition of the SLM-, EBM- and $\mathrm{EBF}^{3}$ produced Ti-6Al-4V parts. The X-ray pattern of the studied samples contains alpha and beta phases, however, the evidence of the presence of the $\beta$-Ti phase within the SLM and EBM parts is only an asymmetric broadening of the XRD peak at $2 \theta=40.7^{\circ}$ belonging to $\alpha$-Ti (101) (Fig. 2, curves 1,2 ). The volume fraction of the $\beta$-Ti phase in the SLM and EBM parts does not exceed 2 and $4 \%$ correspondingly. At the same time, the X-ray pattern of the $\mathrm{EBF}^{3}$ produced $\mathrm{Ti}-6 \mathrm{Al}-4 \mathrm{~V}$ parts contains XRD peaks of $\beta$-Ti phase located at $2 \theta=39.5^{\circ}$ and $57.0^{\circ}$ are clearly identified, revealing the increase in the $\beta$ phase volume fraction up to $6 \%$.

The SLM-, EBM- and EBF ${ }^{3}$-produced Ti-6Al-4V samples are characterized by the presence of high internal stresses. The values of tensile stresses that are developed in the SLM and $\mathrm{EBF}^{3}$ parts are larger than 1.8 and 1.0 GPa respectively. On the contrary, the compressive stresses of magnitude 1.0 GPa are developed within EBM samples. 


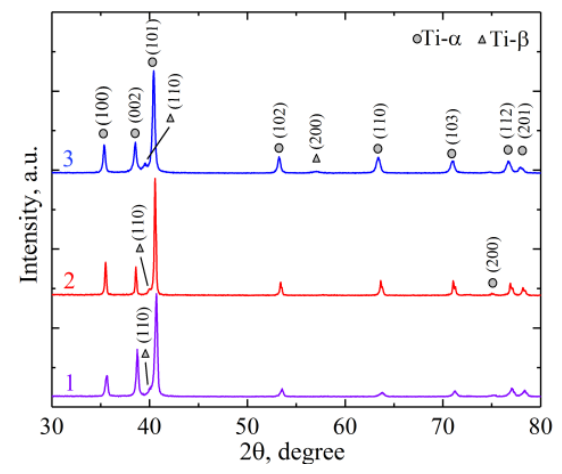

Fig. 2. XRD patterns of the SLM-(1), EBM-(2) and $\mathrm{EBF}^{3}$-produced Ti-6Al-4V samples (3).

Vickers microhardness tests show that the surface hardness of SLM- and EBMproduced $\mathrm{Ti}-6 \mathrm{Al}-4 \mathrm{~V}$ samples are similar (i.e. 5.3 and 5.4 GPa respectively). The surface hardness of $\mathrm{EBF}^{3} \mathrm{Ti}-6 \mathrm{Al}-4 \mathrm{~V}$ parts, in turn, do not exceed $4.5 \mathrm{GPa}$.

\subsection{Strain Response During Tensile Test}

Dislocation slip is a prominent mechanism of plastic deformation in SLM Ti-6Al-4V samples under uniaxial tension. Figure 3, a clearly demonstrates that the length of slip lines is limited by the prior $\beta$-grain boundaries. It is worth noting that the orientation of slip lines in the neighboring grains is different. The spacing between coarse slip lines, and between fine slip lines are equal to 15 and $3 \mu \mathrm{m}$ correspondingly (Fig. 3,b).
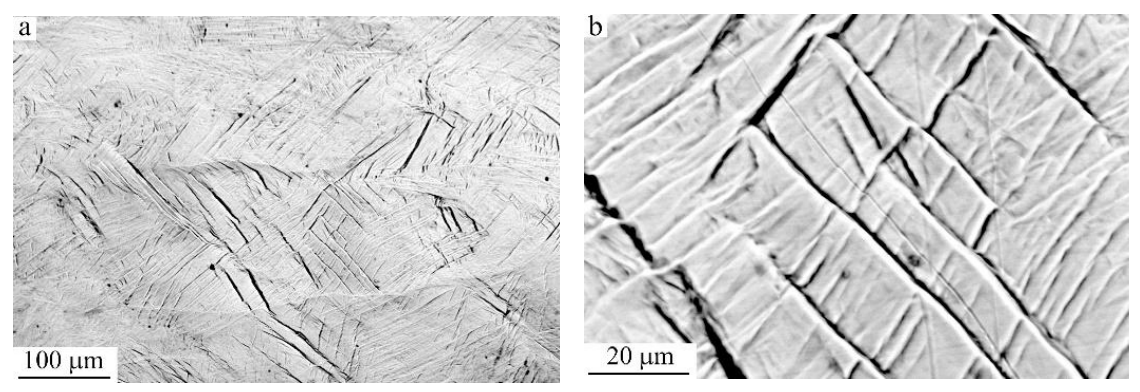

Fig. 3. SEM images of the surface of SLM Ti-6Al-4V samples subjected to uniaxial tension for $\varepsilon=7 \%$.
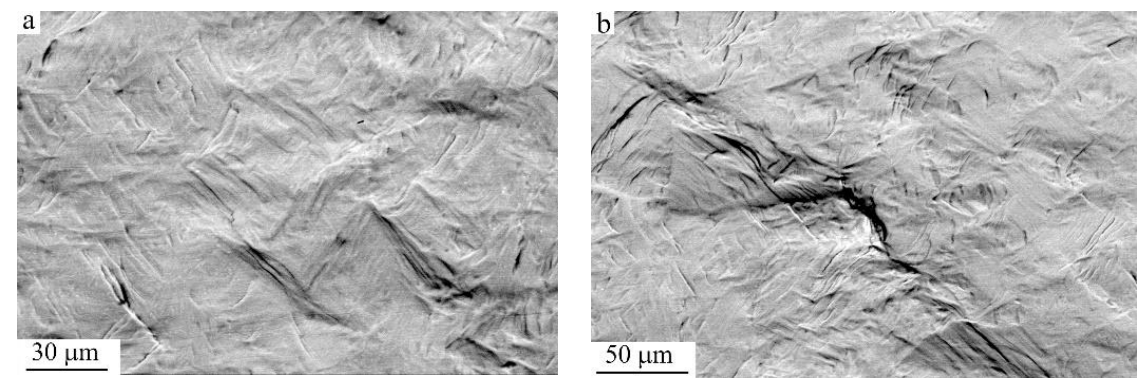

Fig. 4. SEM images of the surface of EBM Ti-6Al-4V samples subjected to uniaxial tension for $\varepsilon=7$ (a) and $13 \%$ (b).

Non-crystallographic shear bands are observed on the surface of the loaded EBM $\mathrm{Ti}-6 \mathrm{Al}-4 \mathrm{~V}$ samples characterized by the smallest prior $\beta$-grain size, they are oriented at $45^{\circ}$ to the loaded axis and propagate through many grains (Fig. 4,a). The deformation by dislocation 
slip most pronounces in prior $\beta$-grain grains in the shear band region. The later evidences that the dislocation glide effectively accommodate the material rotation caused by the displacement of one part of the loaded sample to the other. According to [7] non-crystallographic shear banding in the Ti-6Al-4V sample with a non-equilibrium martensitic structure is associated with plastic lattice distortion and with reversible structural phase transformations.

The intensity of dislocation glide in the $\mathrm{EBF}^{3} \mathrm{Ti}-6 \mathrm{Al}-4 \mathrm{~V}$ loaded samples is also highly inhomogeneous. Different number, spacing and orientation of slip lines are observed in the neighboring packets of lath martensite. As a result, the pre-polished flat surface of the $\mathrm{EBF}^{3}$ Ti-6Al-4V loaded samples exhibits well-pronounced packet boundaries. Optical interference microscopy revealed that submicron height terraces are formed by neighboring packets of lath martensite deformed to different degrees (Fig. 5,a). Moreover, the deformation of blocks of lath martensite (a group of laths of the same orientation) also occurs by dislocation slip limited by block boundaries (Fig. 5,b).
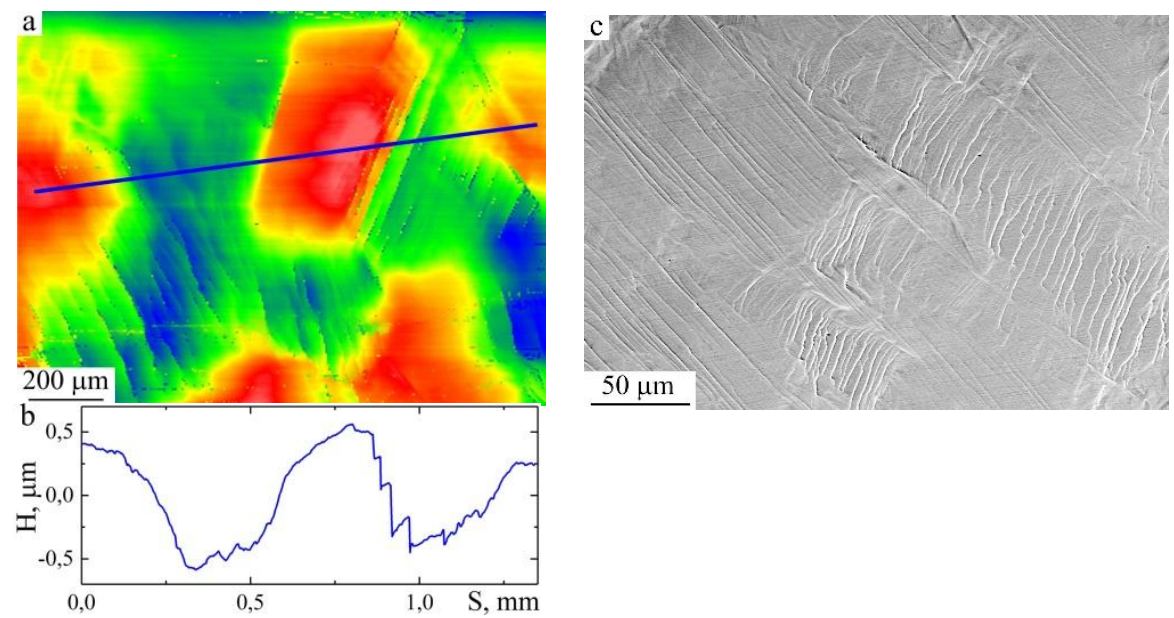

Fig. 5. Images of the surface $(\mathrm{a}, \mathrm{c})$ and corresponding profile (c) of $\mathrm{EBF}^{3} \mathrm{Ti}-6 \mathrm{Al}-4 \mathrm{~V}$ samples subjected to uniaxial tension for $\varepsilon=8 \%$. Optical profilometry $(\mathrm{a}, \mathrm{b})$ and scanning electron mycroscopy (c).

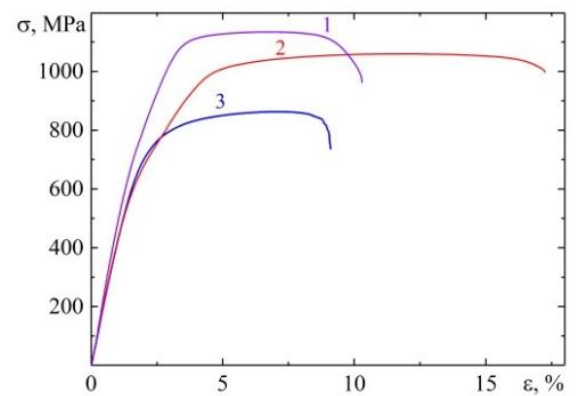

Fig. 6. Tensile engineering stress-strain curves for the SLM-(1), EBM-(2) and $\mathrm{EBF}^{3}$-fabricated Ti6Al-4V samples (3).

Figure 6 shows a comparison in the stress-strain response of $\mathrm{Ti}-6 \mathrm{Al}-4 \mathrm{~V}$ samples fabricated by different additive manufacturing technologies. The ultimate tensile strength and plastic strain of SLM-produced Ti-6Al-4V parts in the as-built state are equal to $1150 \mathrm{MPa}$ and $7 \%$ correspondingly., EBM parts are in turn characterized by a slightly lower ultimate tensile strength (1050 MPa) but extremely high elongation (15\%). However, both the strength and ductility of the EBF3 parts are the lowest $(850 \mathrm{MPa}$ and $6 \%$ 
correspondingly). It is worth noting that the mechanical properties of $\mathrm{EBF}^{3}$-produced Ti-6Al-4V parts are still lower than those of wrought alloys $(930 \mathrm{MPa}$ and $10 \%$ correspondingly).

\section{Summary}

A comparative analysis of the microstructure, strain response during tensile test and mechanical properties of $\mathrm{Ti}-6 \mathrm{Al}-4 \mathrm{~V}$ samples fabricated by different additive manufacturing technologies was performed. The investigations of the $\mathrm{Ti}-6 \mathrm{Al}-4 \mathrm{~V}$ samples produced by Selective Laser Melting, Electron Beam Melting or Electron Beam free-Form Fabrication shown that their microstructures consist of $\alpha$ lathes inside columnar prior $\beta$ grains. EBM samples was characterized by the smallest grain size while the average grain size of $\mathrm{EBF}^{3}$-samples was the biggest. The volume fraction of the $\beta$-Ti phase in the SLM and EBM samples did not exceed 2 and $4 \%$ correspondingly, while that value in the $\mathrm{EBF}^{3}$-samples was equal to $6 \%$.

Dislocation slip was a prominent mechanism of plastic deformation in the SLM-, EBMand $\mathrm{EBF}^{3}$-fabricated $\mathrm{Ti}-6 \mathrm{Al}-4 \mathrm{~V}$ samples under uniaxial tension. Moreover, the noncrystallographic deformation (shear banding) mechanism also operated in the loaded EBM $\mathrm{Ti}-6 \mathrm{Al}-4 \mathrm{~V}$ samples. In the latter case, dislocation glide was most pronounced in prior $\beta$ grain grains in the shear band region. Besides, inhomogeneous dislocation slip in the neighboring packets of lath martensite of the loaded $\mathrm{EBF}^{3}$-samples occurred resulting submicron height terraces on their preliminary polished surface.

The Vickers microhardness of SLM and EBM-produced Ti-6Al-4V samples were similar (i.e. 5.3 and $5.4 \mathrm{GPa}$ correspondingly) while the hardness of $\mathrm{EBF}^{3}$ parts was significantly lower $(4.5 \mathrm{GPa})$.

The comparison of uniaxaial stress-strain response of the additive manufactured Ti-6Al-4V samples have shown that the SLM-fabricated $\mathrm{Ti}-6 \mathrm{Al}-4 \mathrm{~V}$ samples is characterized by the highest ultimate tensile strength (1150 MPa) while EBM samples demonstrated the highest ductility value $(15 \%)$.

The authors gratefully acknowledge the financial support granted by The Russian Science Foundation within the project 18-19-00559.

\section{References}

1. D. Herzog, V. Seyda, E. Wycisk, C. Emmelmann, Acta Mater. 117, 371 (2016)

2. S. Liu, Y.C. Shin, Mater. Des. 164, 107552 (2019)

3. W.E. Frazier, J. Mater. Eng. Perform. 23, 1917-1928 (2014)

4. D. Ding, Z. Pan, D. Cuiuri, H. Li, Int J Adv Manuf Technol. 81, 465 (2015)

5. N. Pushilina, A. Panin, M. Syrtanov, E. Kashkarov, V. Kudiiarov, O. Perevalova, R. Laptev, A. Lider, A. Koptyug, Metals, 8, 301 (2018)

6. A.V. Panin, M.S. Kazachenok, O.B. Perevalova, S.A. Martynov, A.A. Panina, E.A. Sklyarova, Metals, 9(6), 699 (2019)

7. A.V. Panin, M.S. Kazachenok, O.B, Perevalova, E.A. Sinyakova, K.V. Krukovsky, S.A. Martynov, Phys. Mesomech., 21(5), 441 (2018) 